\title{
Improving Corrosion Resistance of Al through Sever Plastic Deformation 1-under Free Condition
}

\author{
M. R. Ebrahim $^{(1)}$, A. E. El Meleigy ${ }^{(2)}$, Sh. E. Abd \\ Elhamid $^{(2)}$ and A. A. Elwarraky ${ }^{(2)}$ \\ (1) Department of Solid State Physics, Metal Physics Lab. and \\ (2) Department of Physical Chemistry, N. R. C., Dokki, \\ Giza, Egypt. PO. 12622
}

\begin{abstract}
THE CORROSION rate of $\mathrm{Al}$ in $3.5 \% \mathrm{NaCl}$ at room temperature 1 can be reduced by subjecting the metal to sever plastic deformation (SPD) through the procedure of surface mechanical attrition treatment (SMAT). The corrosion resistance of grain refined $\mathrm{Al}$ in $3.5 \% \mathrm{NaCl}$ by SMAT for 5, 10, 15, 20 and $25 \mathrm{~min}$ in comparison with $\mathrm{Al}$ as rolled(0) and after annealing for $5 \mathrm{hr}$ at $600{ }^{\circ} \mathrm{C}$ (blank) was investigated by open circuit potential measurement. The results show that as increasing the time of SMAT up to $15 \mathrm{~min}$, the steady state potential $\left(\mathrm{E}_{\mathrm{st}}\right)$ shifted to less negative values. In contradiction, further increasing the time to 20 and $25 \mathrm{~min}$, the potential returned to more negative values. Surface examination using scanning electron microscope (SEM), electron dispersive X-ray (EDX) and X-ray diffraction (XRD) proved that the above results are controlled by the time of oxide film formation. This depends on different factors such as the grain refinement, the segregation of $\mathrm{Fe}$ to the outer surface, the formation of micro cavities, the crystallographic orientation and habit $\mathrm{Al}$ (111) plane phases.
\end{abstract}

Aluminum metal $(\mathrm{Al})$ is alloyed with other elements and thermally treated to improve its mechanical properties, where its alloys find wide applications in many industries. The major alloying additions used with $\mathrm{Al}$ are copper, manganese, silicon, magnesium and zinc; other elements are also added in smaller amounts for grain refinement and to develop special properties. Impurity elements are also present with total percentage of $<0.15 \%$ in $\mathrm{Al}$ alloys such as $\mathrm{Fe}, \mathrm{Si}, \mathrm{Pb}, \mathrm{Cd}$ and $\mathrm{Ti}^{(1,2)}$.

Pure $\mathrm{Al}$ and $\mathrm{Al}$ alloys have relative good corrosion resistance due to the dense oxide film formed on the surface. Accordingly the most common form of corrosion of $\mathrm{Al}$ and $\mathrm{Al}$-alloy is pitting type. It is generally accepted that pitting corrosion is often related to the oxide nature of the film formed on the surface of Al or Al-alloys. Several articles ${ }^{(1-6)}$ concerned about the pitting corrosion of $\mathrm{Al}$ alloys in absence of chloride. The presence of dissolved copper in $\mathrm{Al}$ matrix raises the pitting potential of the $\mathrm{Al}$ alloy ${ }^{(7,8)}$ as a result of the enrichment of $\mathrm{Cu}$ 
on the surface of Al. Therefore, corrosion inhibition of $\mathrm{Al}$ is the most effective method, where organic inhibitors are the most common inhibitors used ${ }^{(9-16)}$. Most of these inhibitors are harmful which might cause serious environment pollutions ${ }^{(17-19)}$.

Recently, refining the microstructure of the metal has attracted great attention to improve metal corrosion resistance ${ }^{(20-26)}$. These occur by subjecting the metal to SPD techniques such as SMAT, equal channel angle pressing (ECAP) and friction stir processing. These procedures lead to increase the grain refinement to become in the sub micrometer or even in the nanometer range ${ }^{(27-29)}$.

Previous studies found that ${ }^{(20,30,31)}$ SMAT are a multi-directional peening process which induces SPD and grain refinement in a thin surface layer. Some authors ${ }^{(20,32-34)}$ reported that SMAT accelerate corrosion rate of $\mathrm{Al}$ as a result of the formation of stresses and defects at which attack may initiate. On the other hand, different authors found that the ECAP process has been noted to increase $(20,21,32,35)$ and decrease ${ }^{(20,36,37)}$ corrosion resistance of $\mathrm{Al}$.

Others ${ }^{(9,20,27,28)}$ found that the corrosion rate of $\mathrm{Al}$ is decreased as grain size decreases.

Most of the above results were conducted using accelerated conditions such as potentiodynamic and potentiostatic polarization or electrochemical impedance spectroscopy which give information about the final stages depending on the techniques used. Accordingly, in this study attention has been focused on the initial stages where SMAT samples are examined after and before immersed in $3.5 \% \mathrm{NaCl}$ under free condition using open circuit potential measurements (OCP). The surface analytical techniques included SEM, EDX and XRD.

\section{Materials and Methods}

The material used in this study was commercial aluminum sheets with chemical composition listed in Table 1 . The $\mathrm{Al}$ sheets were cold rolled to $1.5 \mathrm{~mm}$ thickness then machined to $2 \mathrm{~cm}$ circular disks. Al sheets were annealed for $5 \mathrm{hr}$ in muffle furnace (Heraeus Electronics -Germany) at a constant temperature of $600^{\circ} \mathrm{C}$ to reduce the residual stresses. To reduce the oxidation during the annealing process, the discs were enclosed in $\mathrm{Al}$ foils. Annealed $\mathrm{Al}$ sheets were held inside plastic molds, where the epoxy resin mix was pored and lift to solidify, then polished with increasing grades of Sic emery papers to 1000 mesh. SMAT process was done using built- in laboratory machine in NRC Egypt with a special designed chamber ${ }^{\left({ }^{(3)}\right.}$ has constant number of 33 hard stainless balls. The balls were vibrated in the vertical direction with frequency $50.3 \mathrm{~Hz}$ and amplitude of $1 \mathrm{~mm}$, where they impinging in random directions in air on the surface of Al sheets. SMAT process time was adjusted for increasing times from 5 to $25 \mathrm{~min}$ in air to induce sever plastic deformation of preannealed $\mathrm{Al}$ sheets. The surface treated $\mathrm{Al}$ sheets analyzed with several surface 
examination methods like scanning electron microscope (SEM), energy dispersive $\mathrm{x}$-ray $(\mathrm{EDX})$ and $\mathrm{x}$-ray diffraction $(\mathrm{XRD})$ which were described elsewhere ${ }^{(39)}$.

Open circuit potentials were monitored as a function of time until steady state values were attained. Potential were measured relative to a saturated calomel electrode (SCE) using a PS6 Meinsberger Potentiostat/ Galvanostat, Germany. The exposed area of the electrode to solution was only the circular surface of $3.14 \mathrm{~cm}^{2}$. Measurements were carried out in $3.5 \% \mathrm{NaCl}$ at room temperature after and before SMAT treatments.

TABLE 1. Chemical Compositions of Al .

\begin{tabular}{|c|c|c|c|c|c|c|c|c|c|c|c|c|c|}
\hline Al & $\mathrm{Si}$ & $\mathrm{Fe}$ & $\mathrm{Zn}$ & $\mathrm{Ag}$ & $\mathrm{Mg}$ & $\mathrm{Cd}$ & $\mathrm{P}$ & $\mathrm{S}$ & $\mathrm{Cu}$ & $\mathrm{Ca}$ & $\mathrm{Cr}$ & $\mathrm{k}$ & $\mathrm{Ti}$ \\
\hline 99.1 & 0.854 & 0.027 & 0.003 & 0.002 & $\mathrm{BDL}$ & $\mathrm{BDL}$ & 0.011 & $\mathrm{ND}$ & 0.002 & 0.000004 & 0.000022 & 0.000006 & $\mathrm{BDL}$ \\
\hline
\end{tabular}

ND: Not Detected

BDL: Below Detection Limit

\section{Results and Discussion}

\section{Potential-time behavior}

The effect of SMAT time on potential-time behavior of $\mathrm{Al}$ in $3.5 \% \mathrm{NaCl}$ was studied. The measurements were carried out by means of open-circuit potential (OCP) as in Fig. 1. The curves of Fig. 1 represent the variation with time of the potential of $\mathrm{Al}$ electrode without annealing (zero) and after $5 \mathrm{hr}$ annealing at $600^{\circ} \mathrm{C}$ before (blank) and after different time of 5, 10, 15, 20 and 25 min, SMAT which immersed in $3.5 \% \mathrm{NaCl}$ solution for $120 \mathrm{~min}$. In all cases the potential changed to more cathodic values after the first moment of immersion as a result of the dissolution of the pre-immersion oxide film on the metal surface ${ }^{(40)}$.

In case of zero time annealed $\mathrm{Al}$ and blank sample the potential of the $\mathrm{Al}$ electrode shifts towards more negative value and the steady state potential are obtained from less negative value and only after relatively long periods of initial undulations as a result of the formation of $\mathrm{Al}$ oxides. The larger shift of potential in case of annealed sample (blank) is due to first, the energy stored during the cold-working process is released, which increases its activity. Second the segregation of Fe to the surface with a small ratio can affect increasing the rate of dissolution through the galvanic corrosion around the white spots as recorded previously in case of Al-Cu alloys ${ }^{(1,2)}$. This ratio is not enough to cover a sufficient area of the Al surface to become enough for shifting the potential to the more anodic (opposite direction) where the potential of $\mathrm{Fe}$ is more noble than $\mathrm{Al}^{(41)}$.

On the other hand after SMAT of Al, as the time of SMAT is increased up to $15 \mathrm{~min}$, considerably larger anodic shifts in potential are recorded and the steady state potentials, $E_{\text {st., }}$, are more readily attained. $E_{\text {st. }}$ shifted towards more 
noble value from $-810 \mathrm{mV}$ without SMAT ( blank) to $-730 \mathrm{mV}$ after $15 \mathrm{~min}$ SMAT of Fig. 1. The effect can be explained as being a result of effect of grain size variation on the corrosion resistance of $\mathrm{Al}^{(20)}$. Previous studies ${ }^{(42,43)}$ concluded that the fine grain structure have more reactive surfaces to form oxide film and film ion conduction. This is in agreement with the result of Fig. 1 where the passive film of Al oxide is formed more rapidly at $15 \mathrm{~min}$. SMAT in comparison to blank and other shorter time of SMAT of 5 and 10 min.

In contradiction of this fact by increasing the time of SMAT to 20 and 25 min of Fig. 1, the potential of Al electrode returned to become more negative values than that recoded after $5 \mathrm{~min}$. In this case, some defects on the surface were observed where some dust of Al sample was lied out to the bottom of the SMAT cell. This occurs beside the increase in the number and size of micro cavities over the surface as will be confirmed later using surface examination techniques.

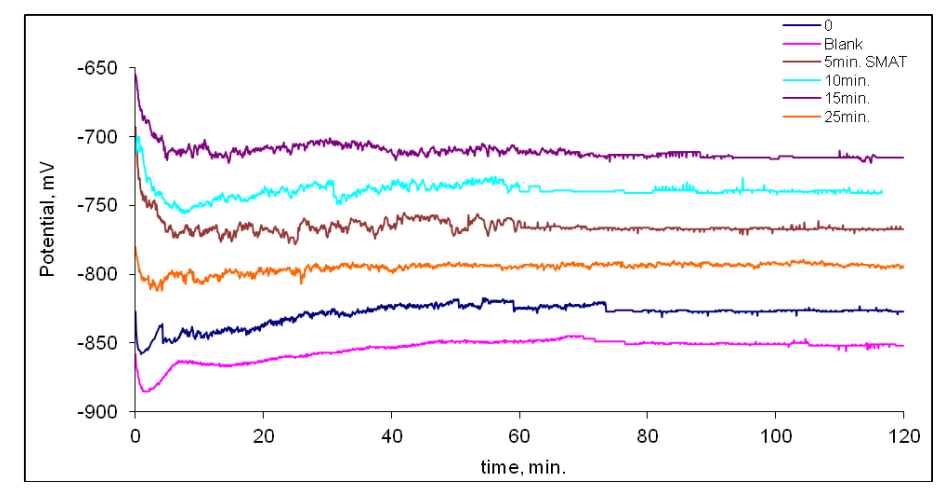

Fig.1. Variation of the open circuit potential of $\mathrm{Al}$ in $3.5 \% \mathrm{NaCl}(0$ time annealed and after $5 \mathrm{hr}$ annealing before and after different time of SMAT.

Spectroscopic analysis measurements

Examination of the surfaces of $\mathrm{Al}$ before and after SMAT, also after OCP treatments were studied using SEM, EDX and XRD techniques.

\section{SEM and EDX examination}

In order to gain insight into the nature of surface of $\mathrm{Al}$ after equilibration in $3.5 \% \mathrm{NaCl}$ using OCP measurements, it is necessary to examine the surface of $\mathrm{Al}$ before and after the OCP measurements of Fig. 1 using SEM as shown in Fig. 2. Figure 2 (a) shows the surface of the pretreated $\mathrm{Al}$ metal using polishing with the emery paper only and after immersion in $3.5 \% \mathrm{NaCl}$ for $120 \mathrm{~min}$ at the end of experiment of Fig. 1. The surface of Fig. 2(a) exhibits a corrosion product which is extended over the whole surface. Fig. 2 (b) shows the back scatter electron detector

Egypt. J. Chem. 59, No. 4 (2016) 
image of cross section $\mathrm{Al}$ metal (0 time annealed), the picture shows that, the appearance of grain structure which is formed as a result of mechanical rolling deformation which occurs during the manufacturing of $\mathrm{Al}$.

Examination of $\mathrm{Al}$ surface after $5 \mathrm{hr}$ annealing at $600^{\circ} \mathrm{C}$ without SMAT (blank) at the end of OCP of Fig. 1 are shown in Fig. 2(c). The picture of Fig.2(c) shows that the appearance of different white and black spots which are extended at scattered area with a very low proportion on the surface. The corresponding EDX analysis of Table 2 over the whole surface represents $\mathrm{Al} 84$ and $\mathrm{O} 15.82 \%$ atomic ratios. At the same time the EDX analysis of white spots exhibits the appearance of $\mathrm{Al}$ 82, Fe 6.7 and $\mathrm{O} 10.76$ atomic ratios. The detection of $\mathrm{Al}$ in this ratio with $\mathrm{Fe}$ was not due to its presence with Fe inside the white spots but it is due to the detection of $\mathrm{Al}$ from the substrate, which lies beneath the detection limit for EDX beam escape depth. On the other hand, the small ratio of oxygen detected does not mean that this is the true ratio because the scape depth of EDX technique is higher than the thickness of the thin oxide film formed. Accordingly the appearance of oxygen with this small ratio gives an indication on the formation of oxide and confirms that there is no any type of $\mathrm{Cl}$ salts.

\section{After 5 min SMAT}

The surface examination of $\mathrm{Al}$ after annealing and SMAT for 5 min using SEM examination was shown in Fig. 3. The back scatter electrons image of Fig. 3(a) shows phase contrast between $\mathrm{Al}$ and $\mathrm{Fe}$ where, Fe which was segregated to the outer surface as indicated from the white scattered regions (black arrows). On the other hand the black region indicates surface accumulation micro-cavities due to habit plane glide of crystallographic faces after sever plastic deformation as aimed to by the white arrows. Increasing magnification as in Fig. 3(b) where, the picture shows a small part of Fig. 3(a), inside the rectangle after magnification revealed that the clustered micro-cavities became clearer beside the appearance of the habit plane glide of face centered (FCC) $\mathrm{Al}$ of 90 angle degrees.

In order to gain insight into the effect of 5 min. SMAT on Al, back scatter electron detector (BSED) cross sections perpendicular to the surface was performed, image of Fig. 3(c) shows a good phase contrast and a new phase of 150 micron in depth from the surface was formed (white color phase). After this thickness (150 microns) the grain boundaries become rich with habit plane glide clustered micro cavities. This occurs as a result of sever plastic deformation SPD and the resultant habit plane multiple glides due to the presence of impurities as Fe, which become clear with increasing magnification as represented by the white arrows and the reciprocal of S shape white curve (Fig. 3(d). On the other hand, the SEM image after OCP measurement of Fig. 1 is not present in Fig. 2 due to its similarity with that recorded in Fig. 2 while the EDX analysis recorded higher values of Fe at both the whole surface and the white spots as in Table 2. 

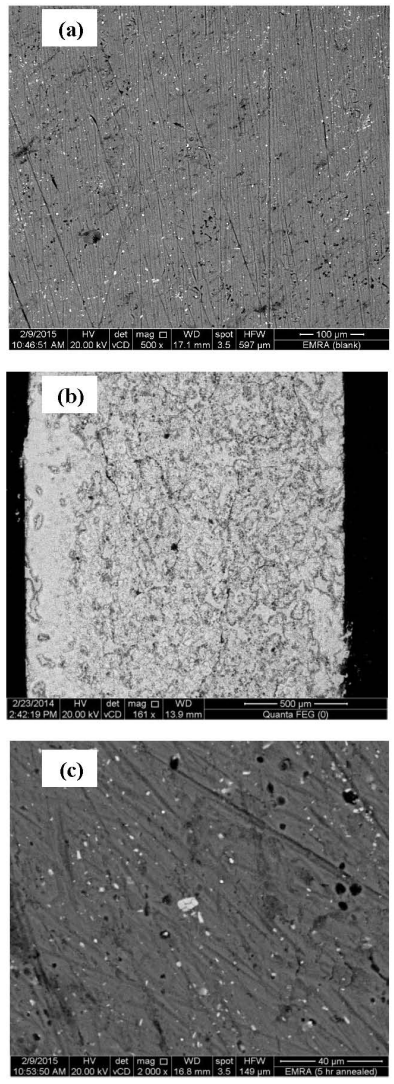

Fig.2. SEM images for $\mathrm{Al}$ metal after treated in $3.5 \% \mathrm{NaCl}$ (after the end of $\mathrm{OCP}$ of Fig.1 where the surface pretreatment are (a) Polishing only with emery paper and this picture was taken after OCP measure (0 sample) (b) Polishing only with emery paper, transverse BSED cross section for Al treated sample after OCP (c) After 5hrs annealing at $600^{\circ} \mathrm{C}$ without SMAT (Blank sample) .

TABLE 2. EDX analysis of SMAT time of Al before and after treatment in $3.5 \% \mathrm{NaCl}$.

\begin{tabular}{|c|c|c|c|c|c|c|}
\hline \multirow{2}{*}{$\begin{array}{c}\text { Time of } \\
\text { SMAT (min.) }\end{array}$} & \multicolumn{4}{|c|}{$\begin{array}{c}\text { Over the major surface } \\
\text { (at. \%) }\end{array}$} & \multicolumn{3}{c|}{$\begin{array}{c}\text { In the white regions } \\
\text { (at. \%) }\end{array}$} \\
\cline { 2 - 7 } & O & Al & Fe & A.C.P of O & Al & Fe \\
\hline Blank & 15.8 & 84.2 & - & 10.76 & 82.32 & 6.7 \\
\hline 5 & 17.5 & 82.0 & 0.5 & 12.2 & 74.3 & 13.5 \\
\hline 10 & 19.66 & 79.8 & 0.54 & 14.5 & 62.11 & 23.39 \\
\hline 15 & 28.29 & 70.71 & 1 & 16.2 & 41.08 & 42.72 \\
\hline 20 & 15.2 & 80.6 & 4.2 & 22.3 & 59.2 & 18.5 \\
\hline 25 & 13.1 & 80.4 & 6.5 & 22.73 & 50.4 & 26.88 \\
\hline
\end{tabular}



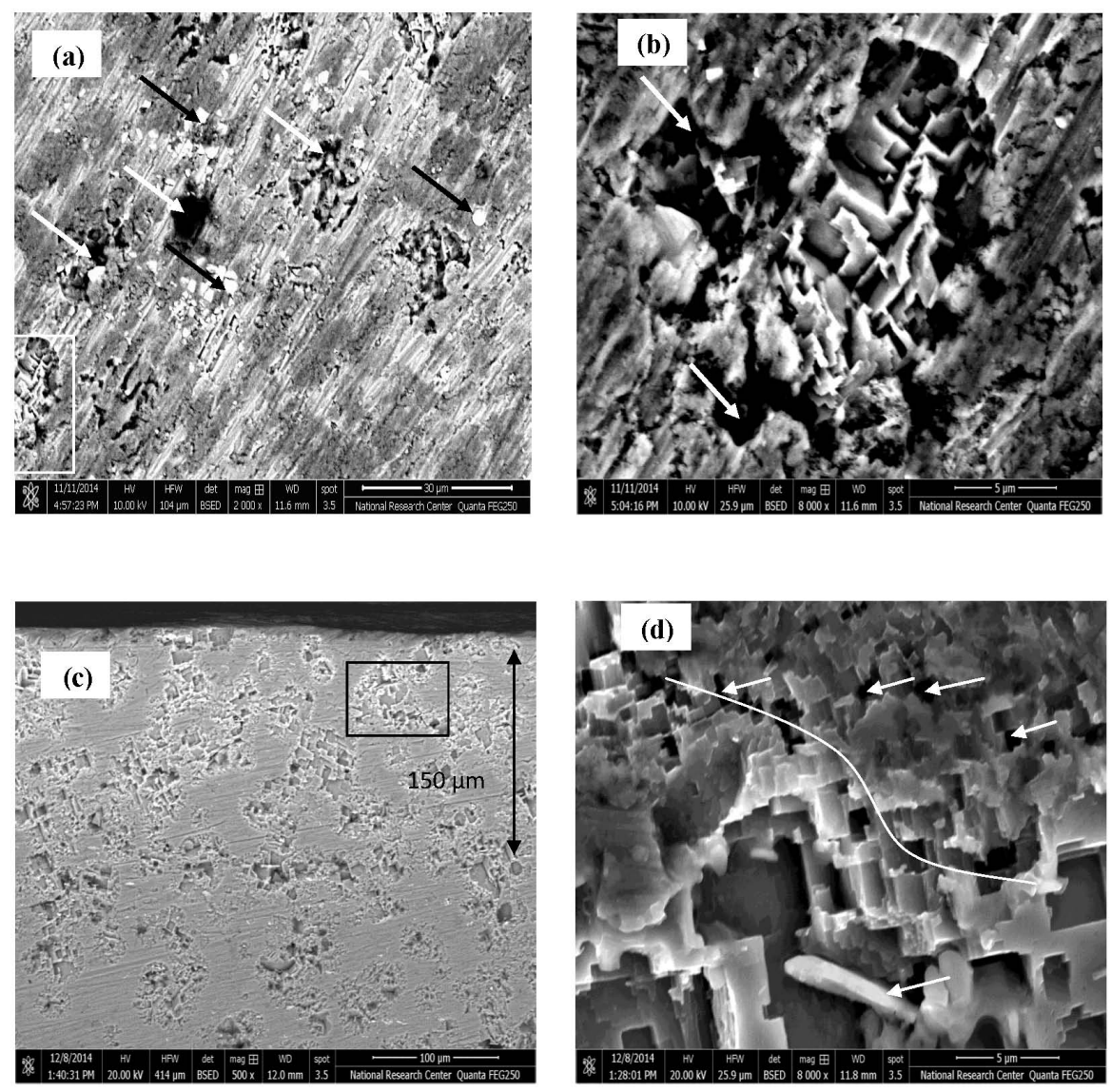

Fig. 3. SEM micrographs showing the surface and cross section of Al after 5 min. SMAT and OCP of Fig.1

a. Surface examination

b. Higher magnification of small part of image (a)

c. BSED cross section.

d. Higher magnification of small part of image (c)

After 10 min SMAT

The surface examination before OCP treatment gives nearly the same results while higher progress in the formation of white and micro cavities regions were detected. Accordingly its figure, was not included due to its similarity with Fig. 3. On the other hand, it was shown that the SMAT improve the surface of Al where, the steady state potential was reached more rapidly within $5 \mathrm{~min}$ for all 
the treated samples as shown in Fig. 1. The SEM micrograph of Fig. 4 shows the surface of Al after OCP measurements, the surface showing an increase in the white regions which scattered over the whole surface. The measured composition of the surface in the white spots as listed in Table 2 had a higher composition of $\mathrm{Fe}$, of $23.39 \%$. This value is bigger than the corresponding value recorded at $5 \mathrm{~min}(13.5 \%)$ and also at the in whole surface of $10 \mathrm{~min}(0.54 \%)$ as in Table 2.

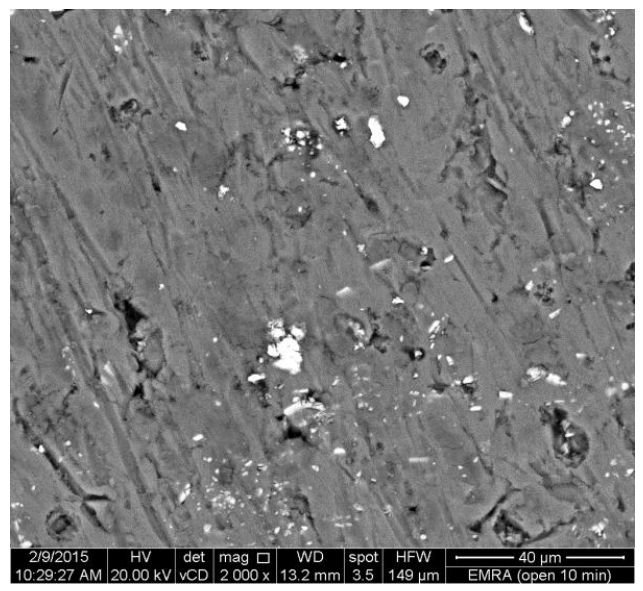

Fig. 4. SEM image showing the surface of Al after $10 \mathrm{~min}$. SMAT and OCP measurement of Fig.1.

After 15 min SMAT

The OCP of Fig. 1 shows that the time required reaching the steady state potential generally decreased with increasing the time of SMAT, whereas the shorter time was recorded after 15 min SMAT.

In the light of the above results, it was necessary to study and examine the surface of Al after SMAT for 15 min without immersion in $3.5 \mathrm{NaCl}$. The surface studies of Al after 15 min SMAT are shown in Fig. 5. The SEM micrograph of Fig. 5(a) shows a greater part of the surface where a small magnification was used (40X). Examination of the surface shows that, most of the surface became plastic deformed (concave regions) as a result of stainless steel balls bombardments. To clarify details, higher magnification $(500 \mathrm{X})$ of Fig. 5(b) shows greater increase in the number of the bright white regions. Such bright Fe-rich regions were evident over the surface due to the segregation of Fe to the outer surface as a result of the effect of stainless steel balls bombardment. On the other hand, clustered micro cavities sites are increased in size and number, which are distributed to cover nearly all surfaces due to SPD. Another observation is also recorded in Fig. 5(c) which

Egypt. J. Chem. 59, No. 4 (2016) 
shows deformed Al surface due to SPD are the deep clustered micro-cavities which elongated as a result of material displacement. The image of Fig. 5(d) shows the cross section of the surface after SMAT for 15 min where, the clustered micro cavities sites are bigger and less dense along the whole surface than those recorded in 5 min SMAT of Fig. 3(c) and also during the first $150 \mu$ in depth from the outer surface. Increasing the magnification from 500X of Fig. 5(d) to $8000 \mathrm{X}$ in Fig.5(e), the picture shows clear clustered micro cavities sites due to deformation as represented by the gray and black regions.

On the other hand, examination of the sample surface of 15 min SMAT after treated in $3.5 \% \mathrm{NaCl}$, at the end of OCP of Fig. 1 is shown in Fig. 6. The image of Fig. 6 (a) shows that the major part of the surface with a small degree of magnification. The surface shows that the formation of different surface crystals sizes between 50 to $170 \mu \mathrm{m}$. It is clearly evident from the higher magnification of 1000x of a small part of Fig 6(a) as represented from Fig. 6(b), the surface shows a large distribution of slip lines of habit planes separated with steps due to deformation and this plane is $\mathrm{Al}$ (111) as will be confirmed later using XRD analysis. Those habit planes are parallel and little inclined and intersecting the surface. Observed surface slip lines are because of individual grains boundaries prefer habit $\mathrm{Al}$ (111) planes in dense polycrystals, almost as if they were independent of the neighboring crystals ${ }^{(44)}$. The surface also suffered from some etching at very small region as represented in Fig. 6(c). Table 2 shows analysis of the surface which represents $70.71 \%$ of $\mathrm{Al}$ and $1 \%$ of $\mathrm{Fe}$ atomic $\%$. The appearance of dislocation crystals grains (Fig. 6(c), with slipped habit planes in contact with the $\mathrm{NaCl}$ solution and intersecting $\mathrm{Al}$ surface which has a fine micro size as a result of the sever plastic deformation by SMAT were responsible for increasing the corrosion resistance as shown in Fig 1. Fig. 6(c) shows one crystal of 170 microns in size where crystallographic habit plane glides for $\mathrm{FCC} \mathrm{Al} \mathrm{(111)} \mathrm{was} \mathrm{formed} \mathrm{due} \mathrm{to}$ the dislocation effect. This crystal is rotated as a result of SPD and to show the surface composition of this crystal, EDX analysis was taken at the center of crystal of Fig. 6(c). Table 2 shows the increase in the concentration of Fe to reach 42.72 at. $\%$ at the center of crystal and 1 at $\%$ over all the surface. These values of $\mathrm{Fe}$ at $\%$ were higher than those recorded under the same conditions for the short time of SMAT. This percentage of Fe is not sufficient to shift the potential to more negative values due to micro galvanic corrosion in comparison with the dislocation effect and orientation which are responsible for improving the corrosion resistance. 

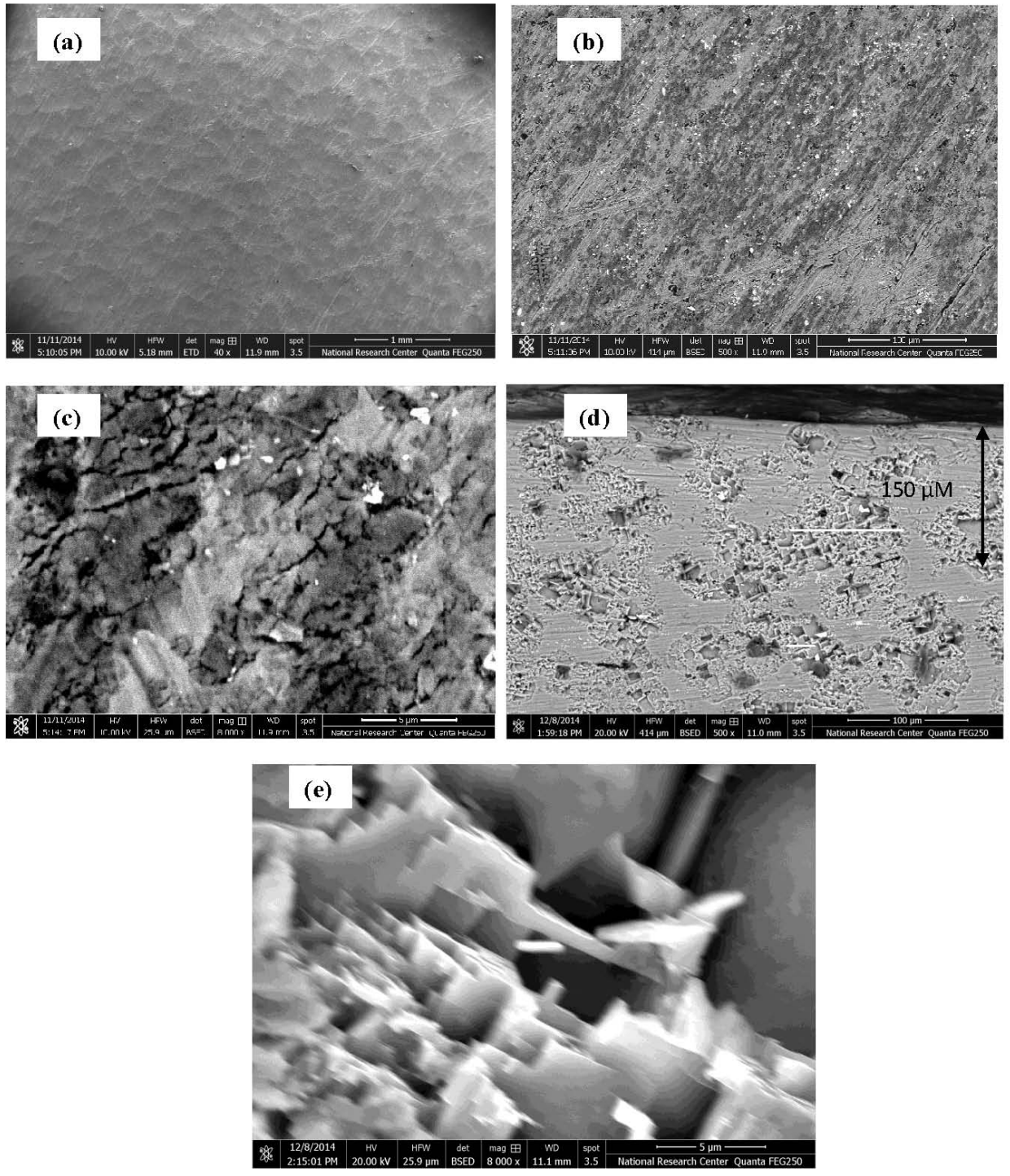

Fig. 5. SEM image showing the surface and cross section of Al after 15 min. SMAT only a. Surface examination which shows a greater part of the surface where a small magnification was used (40x)

b. Surface examination with more magnification $(500 x)$

c. Surface examination with higher magnification $(8000 x)$

d. BSED cross section

e. BSED cross section with higher magnification $(8000 x)$ 

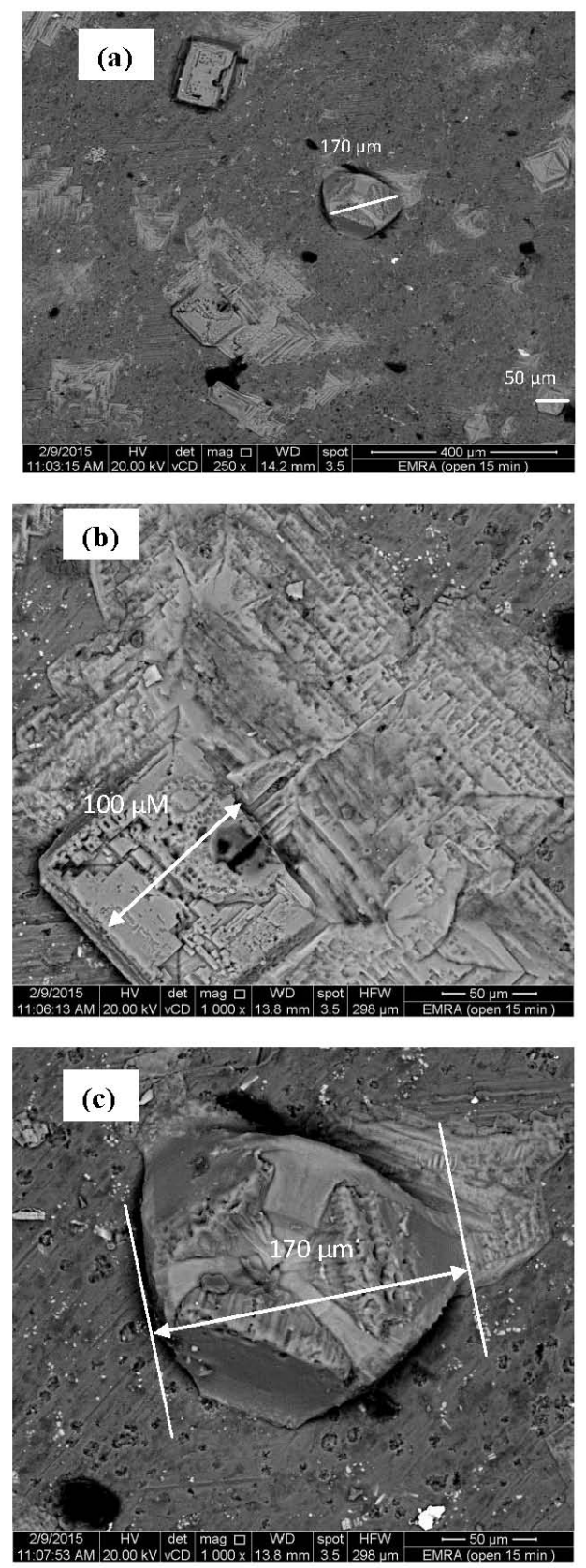

Fig. 6. SEM showing the surface of Al after treated for $15 \mathrm{~min}$. SMAT and OCP of Fig.1.

a. Shows the major part of the surface with a small degree of magnification (250x)

b. Surface examination with higher magnification around one crystal of $150 \mu \mathrm{m}$

c. Surface examination with higher magnification around bigger crystal of $170 \mu \mathrm{m}$ 
After 20 and 25 min SMAT

The effect of increasing time of SMAT of $\mathrm{Al}$ on the potential - time behavior is shown in Fig. 1. It is shown that with increasing the time of SMAT to 20 and $25 \mathrm{~min}$, the potential returned to more negative values to become near to the zero time annealed (blank). These shifts were due to the decrease in corrosion resistance as will be discussed later after surface examination.

The surface examination of $\mathrm{Al}$ after SMAT for 25 min without treatment in $3.5 \% \mathrm{NaCl}$ is shown in Fig.7 which is similar to that recorded at $20 \mathrm{~min}$. The micrograph of SEM of Fig. 7(a) shows that the surface became more plastic concave in comparison with that recorded in Fig. 5(a) at 15 min SMAT. Figure 7 (b) of the higher magnified image of 4000x shows that the bright white region of the surface became more increased in size and number than those recorded at $15 \mathrm{~min}$. The cross section (200x) of the surface after 25 min SMAT (Fig.7 (c) indicates that the clustered micro cavities are increased in number and size in comparison with Fig. 5(d) at 15min of (500x) SMAT. Also, the number of micro cavities and its size are decreased during the first $250 \mu$ min depth from the surface to the surface (left part of the picture) than the second $250 \mu \mathrm{m}$ of the left part of the picture. This represents a reverse effect of cavities formation in comparison with that recorded at 5 min SMAT. This occured due to deformation anneal, that means more less dislocation formation and slip planes have returned to their original places. The cross section of Fig. 7(d) at higher magnification indicates that the surface of the sample became non regular where some cavities and cracks are produced on the outer most surface due to SPD time effect. These defects are the main factor beside the higher increase in Fe segregation to the surface which is responsible for the shift in potential to more negative value as represented in Fig 1. These are in agreement with previous data ${ }^{(20)}$ which concluded that SMAT has been accelerating corrosion due to the defects at which attack may initiate.

Examination of the sample after immersed in $3.5 \% \mathrm{NaCl}$ for $120 \mathrm{~min}$ at the end of experiment of Fig. 1 is shown in Fig. 8 and Table 2. The micrograph reveals that the surface exhibited higher ratio of white regions due to $\mathrm{Fe}$ segregation in comparison with that recorded before $\mathrm{NaCl}$ treatment. This is confirmed from the corresponding EDX analysis of Table (2) which represents the increase in concentration of Fe over the entire sample to reach 6.5 at \% and the decrease in concentration of $\mathrm{O}$ to 13.1 at $\%$ in comparison with the shorter SMAT time. While on the white spot of Fig. 8, the EDX analysis shows $22.73 \%$ $\mathrm{O}$ and $26.88 \mathrm{Fe}$. These observations confirm the higher shift in potential to more negative values as in Fig. 1 of Al after SMAT to 25 min which attain nearly the steady state potential of $\mathrm{Al}$ at zero SMAT.

From the above results it's clearly indicated that although the increase in $\mathrm{Fe}$ on the surface to reach $6.5 \%$ over the entire surface, the metal assumes a potential more negative than Al. This is not in accordance with mixed potential theory ${ }^{(1)}$ where the potential of Fe is nobler than Al. This occurs due to the competition which produced between the improvement of the surface corrosion

Egypt. J. Chem. 59, No. 4 (2016) 
resistance due to the SMAT and the dissolution due to the increase in micro cavities formations and the at. \% of $\mathrm{Fe}$ on the surface which increases the microgalvanic corrosion.
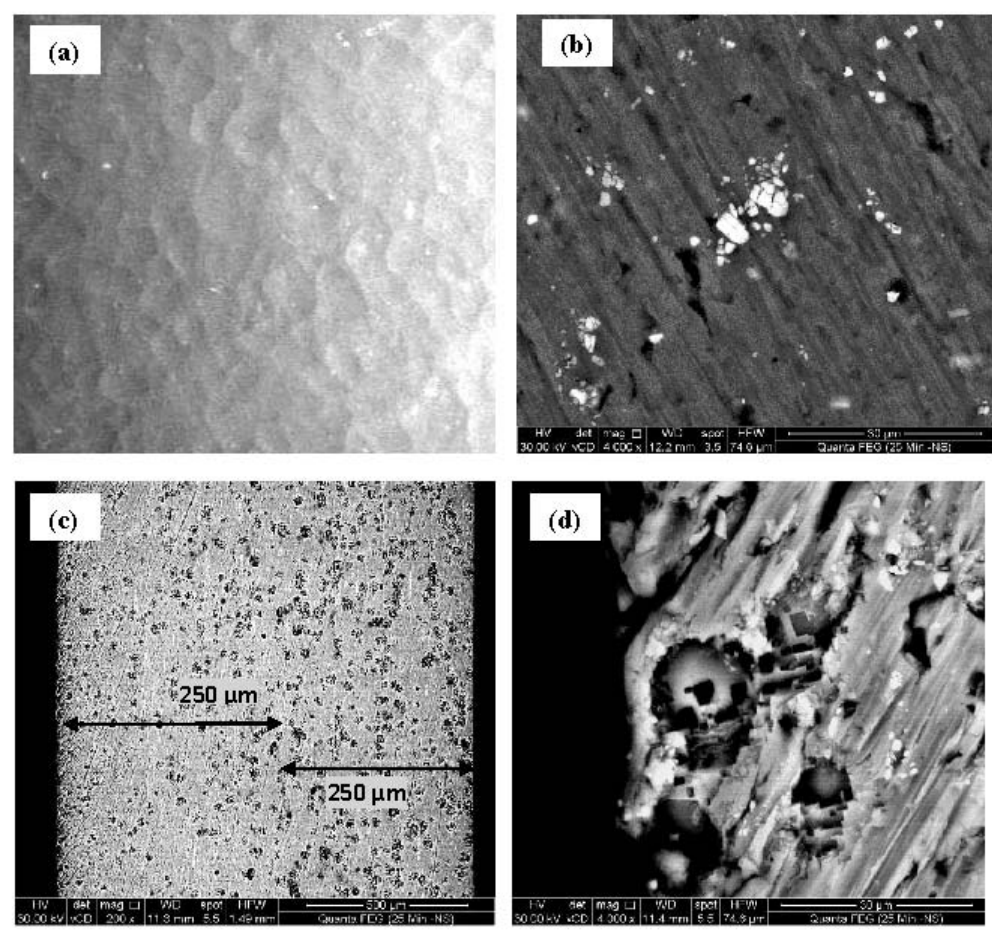

Fig. 7. SEM image showing the surface and cross section of Al after 25 min SMAT only a. With a small magnification $(40 x)$

b. With a higher magnification (4000x)

c. BSED cross section of low magnification $(200 x)$

d. BSED cross section of higher magnification $(4000 \mathrm{x})$

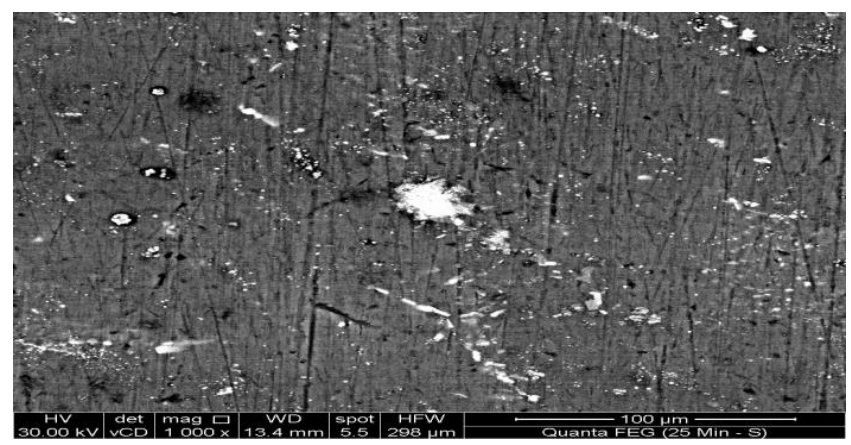

Fig. 8. SEM image showing the surface and cross section of Al after 25 min SMAT.

Egypt. J. Chem. 59, No.4 (2016) 
$X R D$

SMAT time increase affects crystallographic orientation of $\mathrm{Al}$ sheets, that reaching maximum after $15 \mathrm{~min}$ for habit $\mathrm{Al}(111)$ plane in [110] direction as shown in Fig. 9 which represents that a maximum intensity was recorded at $15 \mathrm{~min}$ in comparison with those recorded before (blank) and after (5, 10, 20 and $25 \mathrm{~min}$. SMAT). Crystallite sizes after SMAT, for 5, 10, $15 \mathrm{~min}$ are 56.2, 51.3 and $57.15 \mathrm{~nm}$ SMAT, respectively which calculated using diffractometer software after corrections while after 20 and $25 \mathrm{~min}$. It is difficult to measure the crystalline size as a result of the formation of multi-phase. These results indicated that as increasing the SMAT process time to $15 \mathrm{~min}$, the grain refinement was increased which affect habit $\mathrm{Al}$ (111) plane slipping, shear and peak broadening. Therefore, as increasing the (111) plane faces on the surface, $E_{s t}$ is shifted to less negative values as in Fig. 1 which confirms its effect on corrosion resistance. This conclusion is in accordance with the published data by David et al. ${ }^{(44)}$ which concluded that the (111) plane has the highest coordination number among other planes in the FCC structure and suggested that this is the plane of minimum energy for slipping which is more resistance to corrosion ${ }^{(45)}$.

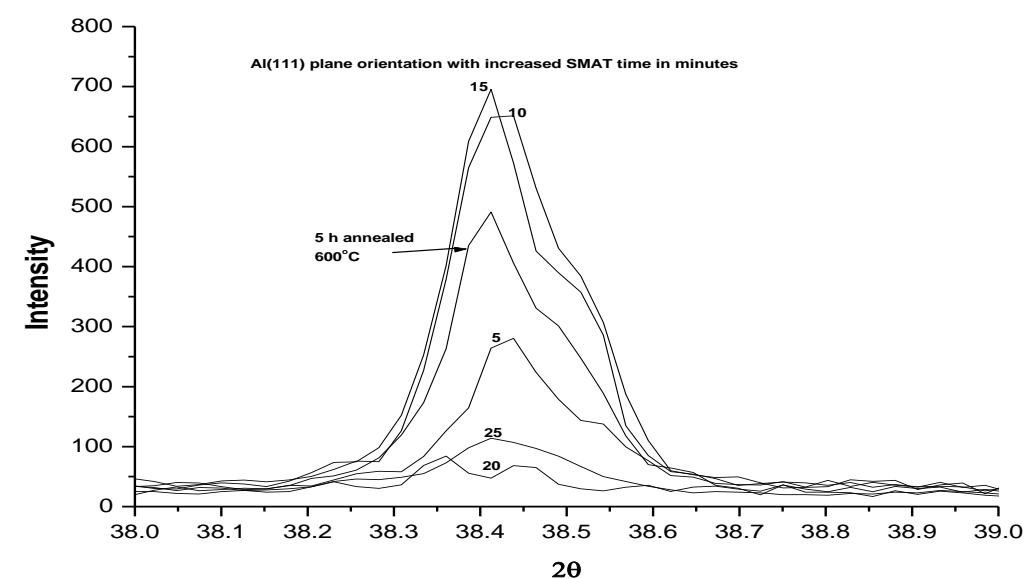

Fig. 9. Al (111) plane orientation with increased SMAT time in minutes .

\section{Conclusions}

The OCP of $\mathrm{Al}$ of 0 time of annealing (0) and after $5 \mathrm{hr}$ annealing at $600^{\circ} \mathrm{C}$ (blank) beside 5, 10, 15, 20 and 25 min SMAT were followed as a function of time in $3.5 \% \mathrm{NaCl}$ until steady state values were obtained. These indicated that:-

(1) In all cases, the potential changed to more cathodic values after the first moment of immersion as a result of the dissolution of the pre-immersion oxide film on the metal surface.

Egypt. J. Chem. 59, No. 4 (2016) 
(2) In case of zero and blank sample, $\mathrm{E}_{\mathrm{st}}$ is obtained at more negative potential and after long periods of initial undulation due to the formation of $\mathrm{Al}$ oxides.

(3) As the time of SMAT is increased up to $15 \mathrm{~min}$, considerably larger anodic shifts in potential are recorded and $E_{\text {st. }}$ are more readily attained. This occurs as a result of the effect of grain size refinement on the corrosion resistance, where the passive film of $\mathrm{Al}$ oxide is formed more rapidly after 15 min SMAT as a result of SPD .

(4) In contradiction by increasing the time of SMAT to 20 and 25 min the potential of $\mathrm{Al}$ returned to more negative values as a result of the appearance of some defects on the surface beside the increase of the number and size of micro cavities produced due to the dislocation effect where attack may initiate.

(5) The surface examination proved that the above results are controlled by different factors

(a) The percentage of segregated Fe to the surface.

(b) The number and size of micro cavities produced due to SMAT.

(c)The effect of SMAT time on grain size refinement, the crystallographic orientation of habit $\mathrm{Al}(111)$ plane.

\section{References}

1. El Warraky, A.A., El-Aziz, A.M. and Soliman, Kh. A., Copper redeposition and surface enrichment during the dissolution of $\mathrm{Al}-\mathrm{Cu}$ alloys in different concentrations of $\mathrm{NaCl}$ solution Part 1 electrochmical measurements. Anti-Corros Method and Materials, 54(3), 155-162 (2007).

2. El Warraky, A.A., El-Aziz ,A.M. and Soliman, Kh. A., Copper redeposition and surface enrichment during the dissolution of $\mathrm{Al}-\mathrm{Cu}$ alloys in different concentrations of $\mathrm{NaCl}$ solution Part 2 spectroscopic analysis measurements. Anti-Corros Method and Materials, 54(3), 163-172 (2007).

3. Buchheit , R.G., Martinez, M.A. and Montes,L.P., $\mathrm{Cu}$ redistribution and surface enrichment due to dissolution of Al-Cu alloys, Localized Corrosion, Proceeding of the Research Topical Symposium, Corrosion 2001, NACE, Houston, USA, pp.265. (2000a).

4. Buchheit, R.G., Grant, R. P., Hlava, F., Mekenzie, B. and Zender, G.L., Local dissolution phenomena associated with $\mathrm{S}$ phase $\left(\mathrm{Al}_{2} \mathrm{CuMg}\right)$ particles in aluminum-

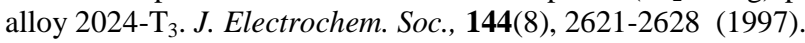

5. El Warraky, A.A., El-Aziz, A.M. and Soliman, Kh. A., $\mathrm{Cu}$ Redeposition and surface enrichment during the dissolution of $\mathrm{Al}-\mathrm{Cu}$ alloy in $0.1 \mathrm{M} \mathrm{HCl}$. Egypt. J. Chem. 48(5), 529-544(2005). 
6. Ramgopal, T., Goum, P.I. and Frankel, S.G., Role of grain -boundary precipitates and solute-depleted zone on the intergranular corrosion of aluminum alloy 7150. Corrosion, 58, 687-697(2002).

7. Blankwood, D.J. and Chong., A.S.L., Influence of chloride on deposition of copper on 6063 aluminium alloy. Brit. Corros. J. 33 , 225-229(1998).

8. Muller, I.L. and Galvele, J.R., Pitting potential of high purity binary aluminium alloys-I. Al-Cu alloys pitting and intergranular corrosion. Corros. Sci. 17, 179193(1977)

9. El-Sayed, M. Sherif, Mahmoud, S. Soliman, Ehab, A. El-Danof and Alnajid, A.A., Effect of equal -channel angular pressing passes on the corrosion behavior of 1050 aluminum alloy in natural seawater. Int. J. Electrochem. Sci., 8, 11031116(2013).

10. Sherif, E, M. and Park, S.M., Effects of 1,5-naphthalenediol on aluminum corrosion as a corrosion inhibitor in $0.50 \mathrm{M} \mathrm{NaCl}$. J. Electrochem. Soc., 152(6), 205-211(2005).

11. Ogurtsov, N.A., Pud, A.A., Kamarchik, P. and Shapoval, G.S., Corrosion inhibition of aluminum alloy in chloride mediums by undoped and doped forms of polyaniline. Syth. Met. 143, 43-47(2004).

12. Obotl, I.B. and Obi-Egbedi, N.O., Ginseng root: A new efficient and effective ecofriendly corrosion inhibitor for aluminium alloy of type AA 1060 in hydrochloric acid solution. Int. J. Electrochem. Sci., 4, 1277-1288 (2009).

13. Bansiwal, A., Anthony, P. and Mathur, S.P., Inhibitive effect of some Schiff bases on corrosion of aluminium in hydrochloric acid solutions. Brit. Corros. J, 35(4), 301-311 (2000) .

14. Brett, C.M.A., Gomes, I.A.R. and Martins, J.P.S., The electrochemical behaviour and corrosion of aluminium in chloride media. The effect of inhibitor anions. Corros. Sci., 36(6), 915-925 (1994).

15. Sayed. S. Abdel. Rehim, Hassam H.H. and Amin, M.A., Corrosion and corrosion inhibition of $\mathrm{Al}$ and some alloys in sulphate solutions containing halide ions investigated by an impedance technique. Appl. Surf. Sci. 187, 279-290 (2002).

16. Zein El Abedin, S., Role of chromate, molybdate and tungstate anions on the inhibition of aluminiumin chloride solutions. J. Appl. Electrochem., 31(6), 711-718 (2001).

17. El Meleigy, A.E., Youssef, G.I., El Shayeb, H.A. and El- Shamy, A.M., Corrosion and corrosion protection of aluminum in hydrochloric acid by using piperidine. Ochrona Przed Korozja, 57(3), 66-71 (2014).

18. El Etre, A.Y., Inhibition of acid corrosion of aluminum using vanillin. Corros. Sci. 43, 1031-1039 (2001). 
19. El-Etre, A.Y., Inhibition of aluminum corrosion using Opuntia extract. Corros. Sci. 45, 2485-2495 (2003).

20. Ralston, K.D., Fabijanic, D. and Birbilis, N., Effect of grain size on corrosion of high purity aluminum. Electrochimica Acta, 56, 1729-1736 (2011).

21. Chung, M.K., Choi, Y.S., Kim, J.G. , Kim, Y.M. and Lee, J.C., Effect of the number of ECAP pass time on the electrochemical properties of $1050 \mathrm{Al}$ alloys. Mat. Sci. \& Eng., A366, 282-291 (2004).

22. Kus, E., Lee, Z., Nutt, S. and Mansfeld, F., A Comparison of the corrosion behavior of nanocrystalline and Conventional Al 5083 Samples. Corrosion, 62(2), 152-161 (2006).

23. Randle, V., Grain boundary engineering: an overview after 25 years. Mat. Sci. \& Tech., 26, 253-261(2010).

24. Mahmoud, T. S., Effect of friction stir processing on electrical conductivity and corrosion resistance of AA6063-T6 Al alloy. J. M. Eng. Sci., 222(C), 1117 (2008).

25. Sikora, E., Wei ,X. J. and Shaw, B.A., Corrosion behavior of nanocrystalline bulk Al-Mg-based alloys. Corros. Sci., 60, 387-398 (2004).

26. Tsai, T. C. and Chuang, T.H., Role of grain size on stress corrosion cracking of 7475 aluminum alloys. Mat. Sci. \& Eng., 225, 135-144 (1997).

27. El-Sayed M. Sherif, Ehab A. El Danaf, Mahmoud S. Soliman and Abdulhakim A. Almajid, Corrosion passivation in natural seawater of aluminum alloy 1050 Processed by equal -channel-angular-press, Int. J. Electrochem. Sci., 7, 2846-2859 (2012).

28. Cheng, X.U., Dobatkin, S.V., Horita Z. and Langdon, T.G., Superplastic flow in a nanostructured aluminum alloy produced using high-pressure torsion. Mat. Sci. \& Eng., A500 , 170-175 (2009).

29. Ehab A El-Danaf, Mechanical properties and microstructure evolution of 1050 aluminum severely deformed by ECAP to 16 passes. Mat. Sci. \& Eng., A487, 189200 (2008).

30. Zhang, H. W., Hei , Z.K., Liu, G., J. Lu, J. and Lu, K., Formation of nanostructured surface layer on AISI 304 stainless steel by means of surface mechanical attrition treatment. Acta Materialia, 51, 1871-1991(2003).

31. Sun, H. Q., Shi, Y. N., Zhang, M.X. and Lu, K., Plastic strain-induced grain refinement in the nanometer scale in a Mg alloy. Acta Materialia, 55, 975-982 (2007).

32. Opt Hoog, C., Birbilis, N. and Estrin, Y., Corrosion of pure mg as a function of grain size and processing route, Adv. Eng. Mat., 10(6), 579-582 (2008).

33. Opt Hoog, C., Birbilis, N., Zhang, M.X. and Estrin, Y., Surface grain size effects on the corrosion of magnesium. Key Eng. Mat., 384, 229-240 (2008).

Egypt. J. Chem. 59, No.4 (2016) 
34. Hao, Y. W., Deng, B., Zhong, C., Jiang, Y.M. and Li, J., Effect of surface mechanical attrition treatment on corrosion behavior of 316 stainless steel, J. Iron and Steel Research International, 16(2), 68-72 (2009).

35. Hellmig, R.J., Janecek, M., Hadzima, B., Gendelman, O.V., M. Shapiro, M. , Molodova, X., Springer, A. and Estrin, Y., A Portrait of Copper Processed by Equal Channel Angular Pressing, Mat. Trans., 49(1), 31-37 (2008).

36. Kutnig, K.V., Papirov, I.I., Tikhonovsky, M.A., Pikalov, A. I., Sivtzov, S.V., Pirozhenko, L.A., Shokurov, V.S. and Shkuropatenko, V.A., Influence of grain size on mechanical and corrosion properties of magnesium alloy for medical implants. Material wissenschaft und Werkstofft-echnik, 40(4), 242-246 (2009).

37. Vinogradov, A., Mimaki, T., Hashimoto, S. and Valiev, R., On corrosion of ultra-Fine Grained Copper Produced by Equi-Channel Angular Pressing, Mat, Sci. Forum, 2-6, 641-646 (1999).

38. Song Dan, Ma Ai-bin, Jiang Jing- hua, Lin pin. hua, Yang Dong-hui , Corrosion behavior of ultra-fine grained industrial pure Al fabricated by ECAP. Trans. Nonferrous Met. Soc. China, 19 , 1065-1070 (2009).

39. Atta, D., Ebrahim, M.R., Grais, Kh.I., Eid, K.A. and Al-Ashkar, E., Spectroscopic analysis of severe plastically deformed Raw Al rolled sheet, Quantum Matter, 5 , 1-6 (2016).

40. Evans, U.R. "The Corrosion and Oxidation of Metals”. Edward Arnold, 898 (1960).

41. wernick,S. and Pinner, R., Second edition, Robert Drapere LTD Teddington, The Surface Treatment and Finishing of Aluminum and its alloys" (1959).

42. Srikant Gollapudi, Grain size distribution effects on the corrosion behaviour of materials, Corros., Sci. 62, 90-94 (2012).

43. Ralston, K.D., Birbilis, N. and Davies, C. H.J., Revealing the relationship between grain size and corrosion rate of metals. Scripta Mater. 63, 1201-1204 (2010).

44. David Saylor, M. Bassem El Dasher, Ying Pang, Herbert M. Miller, Paul Wynblatt, Anthony D. Rollett and Gregory S. Rollett, Habits of grains in dense polycrystalline solids, J. Am. Ceram. Soc., 87(4), 724-726 (2004).

45. Ming Liu, Dong Qiu, Ming-Chun Zhao, Guangling Song and Andrej Atrens, The effect of crystallographic orientation on the active corrosion of pure magnesium. Scripta Materialia, 58 , 421-424 (2008). 


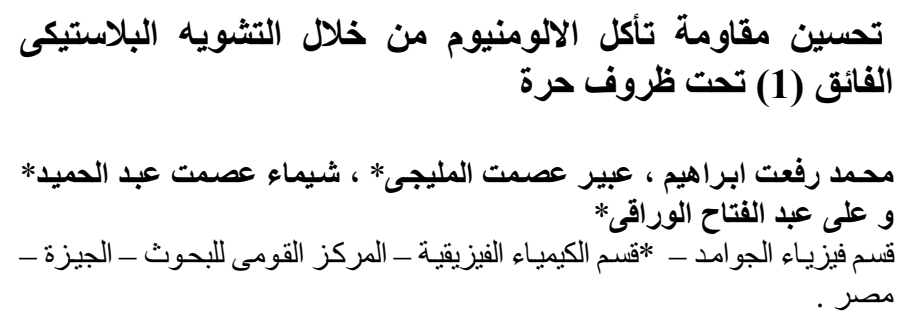

تم تحسين معدل تأكل الالومنيوم فى محلول 3.5٪ من كلور ايد الصوديوم وذلك

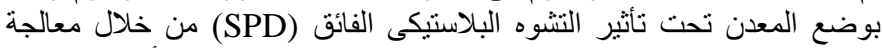

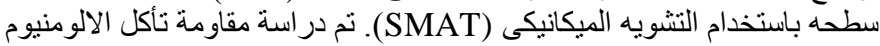

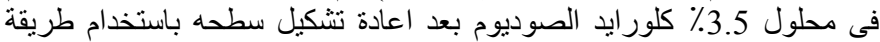

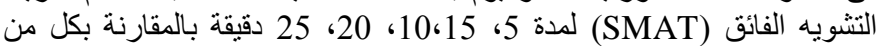

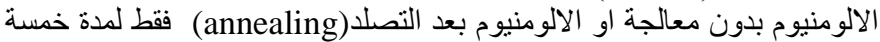

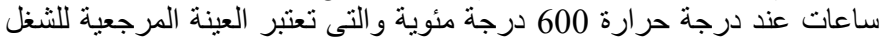

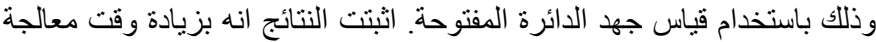

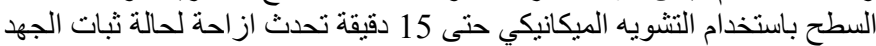
للقيمة الاقل سالبية وبالعكس بزيادة زمن المبادية المعالجة الى 20، 25 دقيقة يتغير اتجاه الجهذ مرة اخرى الى القيمة الاكثر سالبية.

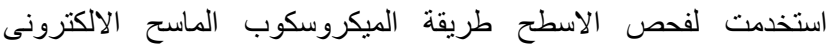
و وتحليله باستخدام طريقة الاشعة السينية المشتخة (SEM)

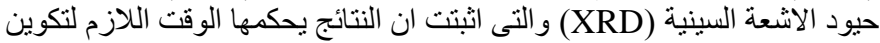

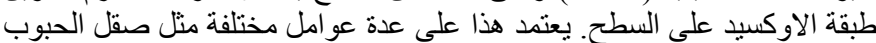

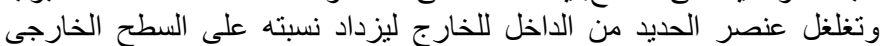

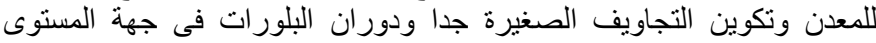

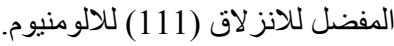

